\title{
Entre a expansão e a sobrevivência: a viagem de Albert Thomas ao Cone Sul da América
}

\author{
Between expansion and survival: Thomas Albert's journey to the \\ Southern Cone of America
}

Norberto Osvaldo Ferreras*

RESUMO

Neste artigo analisarei as relações estabelecidas entre a Organização Internacional do Trabalho (OIT) e os países da América do Sul, mas especificamente, com o Brasil, Argentina, Uruguai e Chile. Para poder apresentar esta relação a nossa analise centrase num momento especifico da mesma, a viagem que realizou em 1925 o Secretario Geral da OIT, Albert Thomas, a estes quatro países. Esta viagem teve como objetivos: a divulgação das ações da OIT e reunir informações sobre a situação do mundo do trabalho nestes países. Também se pretendia insuflar vida a uma relação que até o momento tinha pouco interesse mutuo. Para uma melhor compreensão temos realizado uma breve apresentação da criação da OIT e do seu primeiro Secretário Geral.

PALAVRAS-CHAVE: Trabalho. Organização Internacional do Trabalho. Viagens. América do Sul. Europa.

\section{ABSTRACT}

This article analyzes the relationships between the International Labor Organization (ILO) and the countries of South America, specifically, with Brazil, Argentina, Uruguay and Chile. To present this relationship, our analysis focuses on a specific time, the travel that the General Director of the ILO, Albert Thomas, did to these countries in 1925. This travel aimed to: present the actions of the ILO on these countries and to collect information about the situation of work and the workers in these countries. It also intended to breathe life into a relationship with yet little mutual interest. For a better understanding we have made a brief presentation of the creation of the ILO and its first General Secretary.

KEY-WORDS: Work. International Labor Organization. Travels. South América. Europe.

“Par leur origines, par leur évolutions, ils sont capables, tout à la fois de respecter dans leur dignité et dans leur originalité les aspirations nationales des peuples de la vieille Europe, mas ils sont également capables d'imposer como il convient les pratiques

de paix et de justice qui sont à la base de la Société des Nations"

(Albert Thomas, 1925, referindo-se aos países da América do Sul)

\footnotetext{
* Doutor em História pela Universidade Estadual de Campinas. Professor adjunto da Universidade Federal FluminenseUniversidade Federal Fluminense. Email: norberto.ferreras@ig.com.br
} 


\section{Introdução}

A criação da Organização Internacional do Trabalho (OIT) em 1919 deveu-se, em grande medida, ao esforço realizado por um grupo de socialistas e intelectuais preocupados pelas questões sociais nas negociações que tiveram lugar depois da Grande Guerra. Os conflitos, as resistências, os apoios e as necessidades resultantes do conflito bélico levaram a que fosse criada uma instituição supranacional destinada a lidar com a principal questão social do momento: o Trabalho. No contexto em que foi criada a OIT, via-se como fundamental unificar os sistemas, usos, costumes e legislações que regiam as práticas trabalhistas na Europa e fora dela e que apresentavam uma enorme diversidade. O seu primeiro Secretario Geral, Albert Thomas, foi quem deveu construir a instituição que enfrentasse esta situação. Para tentar convencer os países ${ }^{2}$ a aceitar a nova instituição e o seu esforço por construir uma legislação unificada ele empreendeu viagens ao redor do mundo, do Japão aos Estados Unidos. Entre estas viagens há uma que nos interessa é aquela que ele empreendeu em julho de 1925 aos países do Cone Sul: Brasil, Uruguai, Argentina e Chile, pela ordem de visita.

O objetivo da viagem era dar a conhecer as atividades da OIT, mas também a de conseguir o maior número de ratificações das convenções já aprovadas. ${ }^{3}$ Para conseguir essas ratificações ele utilizava estas viagens para criar uma imagem da OIT como a uma instituição destinada à consecução do bem dos trabalhadores sem ferir as situações especificas de cada país. Neste artigo analisaremos a viagem no contexto da criação e do funcionamento da OIT, da relação estabelecida com a América Latina e das possibilidades abertas pela viagem, assim como focaremos a analise na viagem, para poder compreender as possibilidades de êxito da gestão empreendida. A viagem, assim como tantas outras ações empreendidas por Albert Thomas, teve que ver com a necessidade de construir esta instituição e de dar um sentido à mesma.

\section{A OIT e as Suas Origens}

A OIT tem mais de noventa anos e que se encaminha ao seu Centenário como uma das mais importantes instituições no sistema da Organização das Nações Unidas (ONU), pode-se cair no erro de pensar que desde a sua criação foi de importância ao interior da mesma. Pelo contrario, o nascimento da OIT tem a ver com uma saída de

2. Na primeira Conferência Internacional do Trabalho participaram 40 países e 8 eram da América Latina.

3. A Conferência Internacional do Trabalho, instância deliberativa principal da OIT que se reúne anualmente, aprova uma Recomendação por simples maioria e uma Convenção é aprovada por maioria qualificada de $2 / 3$. 
compromisso numa situação de crise ao interior da incipiente Sociedade das Nações $(\mathrm{SdN})$. Vamos a apresentar brevemente o processo de criação da OIT, desde os seus antecedentes imediatos, para ter uma dimensão do processo.

A OIT foi criada, juntamente com a SdN, por meio do tratado de Paz resultante do fim da Grande Guerra, conhecido como o Pacto de Versalhes. A sua criação data de 1919 e imediatamente foi organizada e dotada com quadros políticos, técnicos e administrativos que, quase que simultaneamente, redigiram-se o seu programa e estabeleceram objetivos, assim como o tipo de vínculo que devia primar com a SdN.

A Seção XIII (ORGANIZAÇÃO INTERNACIONAL DO TRABALHO, 1919) ${ }^{4}$ do Tratado de Versalhes que determinava a criação da OIT não pode ser vista como o seu ponto de partida, pelo contrário a possibilidade da sua criação é produto do tratamento dispensado aos conflitos trabalhistas no período prévio à guerra e durante a mesma. A OIT foi a resultante de uma série de momentos organizativos prévios dos quais participaram os três segmentos que conformam atualmente a OIT: Trabalhadores, Patrões e Estados. Todos eles tinham a sua posição sobre como deveria ser tratada a principal questão social desse momento: a questão do Trabalho. Não há um antecedente único e é difícil estabelecer uma linha continua na conformação desta instituição.

É preciso mencionar que a necessidade de uma instituição como a OIT ou que pudesse dar conta das problemáticas próprias do mundo do trabalho é uma preocupação crescente nas distintas instâncias vinculadas com a questão trabalhista. Outros fatos trouxeram a tona esta preocupação e deram fôlego às reivindicações colocadas pelas lideranças trabalhistas ${ }^{5}$, como a Revolução Russa e a tentativa espartaquista na Alemanha. A pacificação do mundo do trabalho está entre as primeiras preocupações dos encarregados da criação desta instituição, dado que esta paz passa a ser complementar dos acordos políticos, militares e econômicos que foram estabelecidos no Tratado de Versalhes.

A origem da OIT está vinculada a duas questões paralelas: por um lado, a criação de uma instituição que harmonizassem os interesses operários com dos patrões, evitando a luta de classes, e ainda por cima que fizesse isto para além das fronteiras nacionais. Temos que considerar que a demanda dos trabalhadores e a de ser parte da

4.- A conformação da OIT está estabelecida no Tratado de Versalhes na sua Parte XIII, Seção primeira.

5.- Quando falamos em "trabalhadores" ou "lideranças trabalhistas" na OIT, nos referimos a militants ou àqueles que se arrogam o direito da representatividade, como os membros de partidos favoráveis aos interesses dos trabalhadores. 
nova estrutura institucional a nível internacional que está em gestação no imediato pós Grande Guerra.

Por outro lado, não podemos deixar de considerar a versão oficial sobre a criação desta instituição. Esta versão oficial é uma seleção e organização dos fatos que atribuem sentido a uma narrativa específica e que servem para dar sustentação e credibilidade a uma instituição ou a um grupo ao interior da mesma. Este mito é apresentado é apresentado como um longo processo de amadurecimento. A História Oficial da OIT cria uma narrativa consensual e de necessidade em relação a esta instituição. Isto não seria nada de mais e pode ser uma necessidade lógica na criação de uma visão simplificada da história da instituição, para consumo dos próprios funcionários, usufrutuários e visitantes. Uma história simplificada que devêm em memória e, por tanto, numa ossificação dos primórdios que se reitera acriticamente. No mito das origens são trafegadas, uma e outra vez, a noção de harmonia pelo estabelecimento da organização tripartida nos órgãos deliberativos; a lembrança de figuras emblemáticas do socialismo utópico, como Robert Owen, tem por finalidade reunir numa mesma pessoa o empreendedor industrial, o utopista e o benfeitor dos trabalhadores; e a utilização atemporal de conceitos como "justiça social", sem uma definição específica e sem pensar a historicidade e a mutabilidade do conceito e de seus usos. ${ }^{6}$

Os estudos acadêmicos existentes em relação à criação (TOSSTORFF, 2005; ENDRES; FLEMING, 2002) da OIT tendem a sobreestimar a decisão dos grupos que participaram da mesma. A criação da OIT é apresentada como a consecução de um plano para estabelecer e consolidar melhorias para os trabalhadores, embora os grupos que coincidem nesta fundação provenham de tradições e posições diferentes e, além do mais, não sejam unicamente trabalhadores. Aqui primaria a racionalidade dos envolvidos no ideal comum de estabelecer pautas regulatórias das condições de trabalho e do melhoramento das mesmas deixando de lado qualquer outro interesse setorial ou nacional na consecução deste ideal. É uma apresentação um tanto apressada e simplificadora das posições destes trabalhos, mas em grande medida coincidem com as versões oficiais da própria OIT sobre a sua criação. Em ambos os casos são ressaltados os objetivos da colaboração internacional na necessidade de dar entidade e vazão aos desejos do trabalho justo e decente, que na realidade é uma construção terminológica recente da própria instituição.

\footnotetext{
6. Para uma versão oficial da OIT pode ser consultado OIT (1969); a referencia histórica na página
} web da OIT (2010); e ainda RODGERS et al. (2009). 
Mesmo fazendo parte de uma mesma matriz interpretativa os trabalhos acadêmicos nos aproximam a uma realidade muito mais complexa que a enunciada pela OIT. Os estudos sobre a formação e constituição desta instituição mostram os posicionamentos dos distintos atores vinculados às questões trabalhistas, convocados para pensar uma saída aos conflitos que tinham lugar na Europa no período posterior ao fim da Grande Guerra. Mas, esta pauta devia ser aprovada pelos representantes dos países que estavam em negociação, principalmente os Aliados, para que fosse ratificada nas negociações do Tratado de Versalhes de 1919.

O otimismo associacionista do imediato pós-guerra levou a uma conjunção de interesses em favor da criação de um organismo internacional que lidasse com a questão operária. E este otimismo continuou no inicio das negociações do Tratado de Versalhes. Mas, junto ao otimismo a Revolução Russa também é um marco que deve ser considerado. As lideranças trabalhistas envolvidas com a OIT se posicionaram contra os bolcheviques e utilizaram o temor à Revolução para alavancá-la. Este temor, mais do que o otimismo, foi o que finalmente prevaleceu em Versalhes. O acordo, que ameaçava com desmanchar pelo tom das primeiras reivindicações dos delegados trabalhistas, vingou mais pelo temor que pelo otimismo.

Uma mostra da inconsistência deste otimismo torna-se evidente quando pensamos que o Congresso dos Estados Unidos não referendou os acordos alcançados em Versalhes, o que implicou que não participassem nem da OIT nem da SdN. E por outro lado, temos que considerar os resultados das primeiras Conferências Internacionais do Trabalho cujas Convenções e Recomendações tiveram um baixo número de ratificações por parte dos países membros. Na Seção $2^{\underline{a}}$ da Parte XIII do Tratado de Versalhes estabelecia-se uma série de princípios que eram apresentados como de "importância particular e urgente". Estes princípios eram: 1) Não considerar ao trabalho como uma mercancia; 2) a possibilidade de associar-se para operários e patrões; 3) pago de um salário que permitisse um nível de vida digno; 4) a adoção da jornada de 8 horas e a semana de 48 horas; 5) a adoção do descanso dominical de 24 horas; 6) limites ao trabalho infantil; 7) salário igual para ambos os sexos; 8) salário equitativo para todos os trabalhadores dentro de um mesmo país; e 9) a organização de um serviço de inspeção que controlasse as normativas trabalhistas.

Porém, como dito anteriormente, toda a "importância particular e urgente" não foi considerada como tão urgentes pelos países membros. Como vemos nos quadros a seguir que considera os três primeiros anos de funcionamento da OIT: 
Convenção No1 Convênio sobre horas de trabalho (indústria), 1919

\begin{tabular}{|l|l|}
\hline Bulgária & $14: 02: 1922$ \\
\hline Grécia & $19: 11: 1920$ \\
\hline Índia & $14: 07: 1921$ \\
\hline Mianmar & $14: 07: 1921$ \\
\hline Paquistão & $14: 07: 1921$ \\
\hline Romênia & $13: 06: 1921$ \\
\hline
\end{tabular}

Convenção №2 Convênio sobre desemprego, 1919

\begin{tabular}{|l|c|}
\hline Bulgária & $14: 02: 1922$ \\
\hline Dinamarca & $13: 10: 1921$ \\
\hline Estônia & $20: 12: 1922$ \\
\hline Finlândia & $19: 10: 1921$ \\
\hline Grécia & $19: 11: 1920$ \\
\hline Índia & $14: 07: 1921$ \\
\hline Japão & $23: 11: 1922$ \\
\hline Mianmar & $14: 07: 1921$ \\
\hline Noruega & $23: 11: 1921$ \\
\hline Reino Unido & $14: 07: 1921$ \\
\hline Romênia & $13: 06: 1921$ \\
\hline Suécia & $27: 09: 1921$ \\
\hline Suíça & $09: 10: 1922$ \\
\hline
\end{tabular}

C3 Convênio sobre proteção da maternidade, 1919

\begin{tabular}{|l|c|}
\hline Bulgária & $14: 02: 1922$ \\
\hline Grécia & $19: 11: 1920$ \\
\hline Romênia & $13: 06: 1921$ \\
\hline
\end{tabular}


C4 Convênio sobre trabalho noturno (mulheres), 1919

\begin{tabular}{|l|c|}
\hline África do Sul & $01: 11: 1921$ \\
\hline Grécia & $19: 11: 1920$ \\
\hline Índia & $14: 07: 1921$ \\
\hline Mianmar & $14: 07: 1921$ \\
\hline Países Baixos & $04: 09: 1922$ \\
\hline Paquistão & $14: 07: 1921$ \\
\hline Reino Unido & $14: 07: 1921$ \\
\hline Romênia & $13: 06: 1921$ \\
\hline Suíça & $09: 10: 1922$ \\
\hline
\end{tabular}

C5 Convênio sobre idade mínima (indústria), 1919

\begin{tabular}{|l|c|}
\hline Bulgária & $14: 02: 1922$ \\
\hline Estônia & $20: 12: 1922$ \\
\hline Grécia & $19: 11: 1920$ \\
\hline Reino Unido & $14: 07: 1921$ \\
\hline Romênia & $13: 06: 1921$ \\
\hline Suíca & $09: 10: 1922$ \\
\hline
\end{tabular}

C6 Convênio sobre trabalho noturno dos menores (indústria), 1919

\begin{tabular}{|l|c|}
\hline Bulgária & $14: 02: 1922$ \\
\hline Estônia & $20: 12: 1922$ \\
\hline Grécia & $19: 11: 1920$ \\
\hline Índia & $14: 07: 1921$ \\
\hline Mianmar & $14: 07: 1921$ \\
\hline Paquistão & $14: 07: 1921$ \\
\hline Reino Unido & $14: 07: 1921$ \\
\hline Romênia & $13: 06: 1921$ \\
\hline Suíça & $09: 10: 1922$ \\
\hline
\end{tabular}


Como podemos ver, foram poucos os países que ratificaram as convenções sancionadas pela OIT em 1919 e nos três anos seguintes. Os poucos que ratificaram convenções não ratificaram todas, com exceção da Grécia. Estamos delimitando um curto período de tempo e apresentamos unicamente as convenções aprovadas em 1919, mas, mesmo num momento de otimismo pela criação da OIT o apoio é pequeno decidido à mesma. Dos países diretamente envolvidos com a criação da OIT só a Grã Bretanha e a Suíça, sede da OIT, aprovam algumas das Convenções. ${ }^{7}$ A França de Albert Thomas, Secretario Geral da OIT, só vai a aprovar três convenções (as números 2, 4 e 6) em 1925. As coisas mudaram na medida em que a OIT conseguiu sobreviver e começou a receber o apoio de outros países para além dos diretamente envolvidos.

Se a criação da OIT é vista e apresentada como uma retribuição aos trabalhadores pelo seu comprometimento com as democracias na Grande Guerra o interesse por referendar os seus direitos não se refletiu nas ações posteriores. Certamente que a situação política e econômica de pós-guerra transita por carris que não são aqueles esperados, assim como a militância trabalhista não foi aquela é a que as lideranças socialistas ou reformistas lhes propunham. O comunismo e o fascismo emergente foram refratários aos acordos propostos pela OIT, embora a URSS e a Itália participassem da mesma em distintos momentos (ELEY, 2005). Muitos países entendiam estes acordos como uma ingerência na sua soberania.

Por tanto, uma vez alcançado o objetivo principal, a criação da OIT, não há houve muito interesse na consecução dos objetivos secundários, que haviam sido negociados com muito esforço e cuidado. Desta forma a aliança para a fundação se desfez e começou uma nova etapa na História da OIT: a da sua consolidação. Se bem há interesse para a continuidade do seu funcionamento, e por manter a militância trabalhista sob controle, nem todos os países integrantes concordam com o tipo de reivindicações existentes. Nesta nova etapa as alianças estabelecidas se darão em relação a cada uma das temáticas em disputa.

\section{Albert Thomas, Secretário Geral da OIT}

Albert Thomas não é uma das figuras mais conhecidas da política francesa e européia ainda alcançasse importantes posições e participasse de momentos centrais da política francesa durante a Grande Guerra, por isso é preciso fazer uma breve apresentação do primeiro Secretario Geral da OIT para compreender, também, um pouco melhor a sua viagem. Poderíamos dizer que Thomas foi um quadro da primeira

\footnotetext{
7. Em ambos os casos foram quatro convenções das seis propostas.
} 
linha do Socialismo francês, mas não integrou o grupo de personalidades que transcenderam as fronteiras do seu país.

Albert Thomas nasceu em Champigny-sur-Marne, na França, em 1878. Toda a sua trajetória política esteve ligada à Section Française de L’Internationale Ouvrière (SFIO). ${ }^{8}$ Ele iniciou a sua vida política como diretivo da Federação das Cooperativas de Consumo, o que lhe manteve próximo dos trabalhadores socialistas. Em 1904 foi eleito representante distrital e em 1910 chegou a ser representante nacional pela região do Sena. Fez parte do entorno de J ean Jaurès, ao ponto de ter-lhe convidado a escrever o volume 10 da História do Socialismo Francês, destinado a analisar o Segundo Império (THOMAS, 1901), foi membro da redação de L'Humanité, de L'Information, da Revue socialiste, e ainda fundou a Revue syndicaliste, e posteriormente L'Information ouvrière et sociale. Durante a guerra, em 1914, foi chamado a organizar a produção de munições, em 1915 foi nomeado Subsecretario de Estado da Artilharia e Munições e, em 1916 chegou ao cargo de Ministro de Armamento (ORGANIZACION INTERNACIONAL DEL TRABAJO, 2006; GUERIN, 1996, p. 6) ${ }^{9}$, cargo ao que renunciou um ano mais tarde depois da crise ministerial que afastou ao SFIO do governo. Mesmo assim continuou a defender a "Guerra pela Paz" e o envolvimento dos trabalhadores na cruzada contra o Kaiser e pela Democracia. Voltou ao Parlamento francês em 1919, agora pelo Departamento do Tarn.

Em 1918, Albert Thomas participou da Conferência Socialista e Operária em Londres, onde foi preparada a minuta que seria elevada pelos trabalhadores à Conferência de Versalhes que tratava o acordo de Paz. J á com a Conferência da Paz em andamento e ante a recusa de Georges Clemenceau, o presidente francês, de permitir a incorporação dos países neutrais, os delegados operários e socialistas dariam continuidade as suas reuniões com um encontro em Berna. Daqui saiu a reivindicação da incorporação de um apartado no Acordo de Paz para que os trabalhadores fossem considerados parte do debate. Os trabalhadores tinham-se sacrificado pela causa da Paz, por tanto, exigiam que suas demandas fossem atendidas. No desenrolar destes encontros Albert Thomas ficou muito bem impressionado com Samuel Gompers, o Secretario Geral da American Federation of Labor (AFL) e o motor destas reuniões, ainda quando este fosse anti-socialista. Ele lhe escreveu uma carta na que dizia que coincidiam com o líder trabalhista dos Estados Unidos na posição de que a guerra tinha

8. Muitas vezes denominado como Partido Socialista Francês, mas que não tem uma relação direta com o atual PSF.

9. Entre os seus colaboradores nesta função estiveram alguns indivíduos que já eram ou deveriam em importantes intelectuais franceses como Maurice Halbawchs e François Simiand. OIT (2006); Guerin (1996, p. 6). 
sido pela emancipação dos trabalhadores e que, por tanto, eles tinham direito à representação nas negociações de paz, mesmo quando tivessem diferenças entre eles. Por tanto os que queriam servir à Democracia e aos Trabalhadores tinham que depor as suas desavenças, porque o inimigo combatido tinha ameaçado as liberdades do mundo (GUERIN, 1996, p. 16).

Albert Thomas, se bem não foi representante oficial na Conferência de Paz, participou das reuniões tentando persuadir aos representantes dos países vencedores a incorporar um ponto especial no tratado, que posteriormente seria incorporado como a Parte XIII do Tratado de Paz de Versalhes. Desta Parte XIII derivaria a criação da Organização Internacional do Trabalho (OIT). No Primeiro congresso da OIT realizado em Washington em 1919, depois de uma série de negociações entre patrões e trabalhadores, os franceses conseguiram eleger a Albert Thomas como o seu primeiro Secretario Geral, preterindo os ingleses que ficaram com o Secretario Adjunto. (SOUZA 1933; GOVERNING BODY OF THE INTERNATIONAL LABOUR OFFICE, 1920, p. 3).

Neste momento Albert Thomas estava isolado ao interior da SFIO. Por um lado tinha ferido o seu relacionamento com Léon Blum, a principal liderança da SFIO depois da morte de J aurès, porque considerava que os socialistas deviam optar entre Lênin e Wilson, ou seja, entre o modelo soviético e a democracia como nos Estados Unidos. Blum respondeu que optava por J aurès, ou seja, pela unidade da SFIO (GUERIN, 1996, p. 10). Posteriormente no debate sobre a criação do Partido Comunista Francês, que se deu no Congresso de Tours em 1920, ficou no grupo minoritário liderado pelo próprio León Blum e que manteve viva a SFIO. ${ }^{10}$ Por isso, nesta situação de minoria dentro da minoria assumir a Secretaria Geral da OIT representava a possibilidade de superar o isolamento em que se encontrava. Inicialmente ele considerava a ida para Genebra, como uma escala intermediaria e necessária para posteriormente retornar à cena da política francesa (GUERIN, 1996, p. 9).11

Mesmo quando este fosse a idéia original, ele se comprometeu com a OIT e a criou, dando-lhe uma organização, um funcionamento e uma missão. A OIT não existia enquanto instituição e foi levantada da nada. Em grande medida, ele demonstrou na sua trajetória anterior e na OIT que era um organizador e um executor. Esta parece ter sido a sua principal virtude. Ele deu um rumo a uma instituição que foi criada num momento de incertezas e mudanças. A OIT foi criada no momento de emergência do

10. Mais dados sobre o acontecido no Congresso de Tours. (ELEY, 2005, p. 216). A implicância de Albert Thomas com o comunismo se manteria como ele manifesta as suas ressalvas sobre esta questão. (OIT, 1996, p. 298), esta é a reprodução do artigo publicado no primeiro numero da revista em 1921.

11. Guerin (1996) cita uma carta de Thomas a um amigo em 1921, para reafirmar esta tese. Porém, ele permaneceu como Secretario Geral da OIT até a sua morte em 1932. 
comunismo e do fascismo, com o paradigma reformista em crise e a democracia decimononica ameaçada, foi preciso criatividade e capacidade de ação para manter vivos os acordos alcançados em Versalhes e Albert Thomas fez a sua parte dentro da OIT.

A OIT precisou ser inventada, criada. Todos os acordos preexistentes não tinham muita importância na hora de impor uma dinâmica e uma metodologia de trabalho. Se bem estavam determinadas certas instituições, como a existência da Conferência Internacional do Trabalho e o Escritório Internacional do Trabalho. O conteúdo ficou por conta da administração, compartilhada pelo Secretario Geral, Albert Thomas e o Secretario Administrativo, o inglês Harold Butler.

Deixando de lado os importantes debates travados entre eles e nas Conferências Internacionais do Trabalho, sobre o tripartismo ${ }^{12}$, a forma de organizar o tripartismo, as implicâncias das Convenções e Recomendações são produto das conceições do socialismo e do internacionalismo de Albert Thomas que estavam circunscritos aos seus interesses principais, derivados da sua formação política e da sua experiência previa como administrador. A sua preocupação principal estava na Europa e todas as suas referências eram européias. Para Denis Guérin, isto se deve a que ele se preocupava por aquilo que podia controlar, pelo que estava ao seu redor, mesmo quando em OIT tenha proporções mundiais, conformada por países de todos os continentes. ${ }^{13}$ Entendo que isto não se limita a uma questão de proximidades, formação política e disputas em relação ao sentido do socialismo, há outros elementos que tem a ver com um determinado momento da Europa e da sua visão de mundo além das suas fronteiras geográficas.

\section{A Viagem ao Sul da América}

Para falar da viagem ao Sul da América temos que analisar a posição da OIT em relação a América Latina e qual o lugar dado a esta parte do hemisfério por Albert Thomas. Inicialmente a posição de Albert Thomas para com o resto do mundo fora da Europa reflete o eurocentrismo vigente entre os intelectuais e políticos europeus. ${ }^{14}$ Este eurocentrismo pode ser visto como capaz de eliminar as alternativas existentes ou de

12. É denominado "tripartismo" o fato de que a OIT se organiza na base da representação de três setores complementares: Estados, operários e empresários.

13. Guerin (1996, p. 3). A lista dos países que participaram da Primeira Conferência Internacional do Trabalho em 1919 está em League of Nations (1920, p. 5-10).

14. Para o "eurocentrismo". Said (1999, p. 56-61). O eurocentrismo não é um elemento menor na ideologia européia, o próprio Marx tinha posições que colocavam a Europa como centro intelectual e cultural, é só lembrar a imagem que ele constrói de Simón Bolívar ou as suas reflexões sobre o trabalho na Índia. (MARX, 2008). 
inviabilizá-las, porque ao monopolizar o inteiro sistema de representações e ao colocarse no ápice da cultura construía e erigia aliados e inimigos nos países coloniais ou periféricos. Os debates das Conferências Internacionais do Trabalho apresentam esta característica, principalmente nas reuniões preparatórias, nas quais se reconhecia como interlocutores aos representantes de países que aceitava o eurocentrismo e se excluía àqueles que contestariam a supremacia européia, principalmente depois que os Estados Unidos não ingressaram na OIT. Os representantes dos países não Europeus são excluídos ou, quando participam, o fazem numa posição marginal, sem peso na hora das decisões, como observadores do protocolo oficial. ${ }^{15}$

Neste sentido as preocupações de Albert Thomas, repassada para a OIT, giravam em torno à construção de uma política de harmonia européia e da defesa dos valores e posições europeus. Neste caso o que entra em questão é o direito trabalhista europeu, que embora está em fase de construção, sem estar consolidado, a pretensão era a de impor as formas, as práticas, os ritmos europeus, inicialmente ao conjunto da Europa e depois fora dela. Os vencedores da Grande Guerra, eram os países industrializados, os que tinham os movimentos operários mais ativos e militantes (com a exceção da derrotada Alemanha), e queriam impor e garantir os seus princípios, a sua legislação e os seus acordos entre Capital e Trabalho, inicialmente ante a Europa periférica e rural, e numa segunda instancia esta legislação devia transcender o continente e se expandir em direção aos países industrializados da América Latina e da Ásia. Mas, uma vez que os Estados Unidos não ingressaram na OIT, o socialismo eurocêntrico de Albert Thomas, se consolidou como a ideologia oficial da OIT.

Como coloca Guerin, a política de Thomas deveu-se à sua preocupação com os problemas europeus, principalmente pelo impacto da própria Grande Guerra. É este fato o que norteia a sua política, ao ponto que ele será qualificado como SocialNacionalista, pelo fato de defender o direito dos estados europeus. Para ele a defesa do direito trabalhista e o europeísmo eram compatíveis. Assim como também entedia as questões trabalhistas como constitutivas das relações internacionais (GUERIN, 1996, p. 10-22).

Temos que lembrar que o esforço da OIT estava em consagrar um regime trabalhista único, mesmo quando não existam acordos definitivos entre os países europeus e dos Estados Unidos. A OIT visava igualar as leis porque a questão que eles apresentam como central era a concorrência desleal daqueles que exploravam os trabalhadores enquanto que outros se esforçavam por melhorar as suas condições de

\footnotetext{
15. Nas sessões preparatórias das primeiras Conferências Internacionais do Trabalho os únicos países representados neste corpo preparatório são a Argentina e o J apão. Para avaliar a importância dada a estes encontros os documentos produzidos são todos encabeçados como "CONFIDENCIAL".
} 
vida. A Seção Primeira da Parte XIII do Tratado de Versalhes da OIT dizia: “Considerando que a não adoção por uma nação qualquer de um regime de trabalho realmente humano põe obstáculos aos esforços das demais nações desejosas de melhorar a sorte dos operários nos seus próprios países”. Esta colocação inicial por parte dos países vencedores da Grande Guerra pode ser vista como ingênua. Porém, dez anos depois, será o próprio Albert Thomas quem ratificará esta mesma apreciação, reafirmando a posição reformadora dos países "avançados" em relação àqueles que exploravam deslealmente aos seus trabalhadores (THOMAS, 1931, p. xiii).

Poderíamos pensar que esta defesa do direito nas bases européias poderia favorecer aos trabalhadores nos países periféricos. Mas, pelo menos no caso argentino, nem todos os trabalhadores se sentiam contemplados pela política da OIT. Para 1925 só os socialistas, que desde o primeiro momento tinham se manifestado a favor da OIT, e os católicos, um grupo minoritário entre os trabalhadores organizados, apoiavam as iniciativas ou eram enviados como representantes trabalhistas argentinos às Conferências Internacionais do Trabalho. Como dizia o representante argentino e especialista em Direito trabalhista, Alejandro Unsaín, ninguém queria carregar com o ônus de aprovar iniciativas que depois não necessariamente eram aceitas pelo conjunto do movimento operário. Por tanto, nem a Federación Obrera Regional Argentina (FORA) liderada pelos anarquistas, nem a Unión Sindical Argentina (USA), de tendência Sindicalista revolucionária, aceitavam participar da representação operaria, sendo que estas eram as centrais operarias com maior numero de filiados (UNSAÍN, 1925).

Mas, para além do Eurocentrismo e do europeísmo de Thomas, há outras duas questões que precisam ser apresentadas e que estão relacionadas, certamente, com sua postura ideológica, mas também com a tarefa que ele se impôs e que lhe impus à sua administração: por um lado, ele pretendia a maior quantidade de ratificações por parte dos países membros, que deviam chegar por meio da diplomacia ou por meio das suas múltiplas viagens. $\mathrm{O}$ outro problema estava na dificuldade para levar à frente as suas políticas com o quadro funcional existente que não era nem quantitativamente nem qualitativamente, suficiente para as necessidades existentes (THOMAS, 1996, p. 294). ${ }^{16}$

Estas duas questões não eram menores e exigiram enormes esforços à administração Thomas. Num momento de nacionalismo em ascensão, de expansão da militância comunista e de surgimento do fascismo, não havia país que quisesse entregar parte da sua soberania aceitando uma legislação que era decidida no exterior. Este será um dos motivos que levaram à Albert Thomas a fazer a viagem ao Cone Sul da América.

16.- Albert Thomas reclama desta dificuldade um ano depois da criação da OIT. 
O próprio Albert Thomas enumerava a quantidades de dificuldades enfrentadas para alcançar cada uma das ratificações:

[...] atrasos administrativos, preconceitos nacionalistas, contradições constitucionais objeções legais, receios econômicos, embaraços próprios dos jogos parlamentares, a oposição de alguns trabalhadores, a indiferença ou a hostilidade da opinião pública, incompreensões e suspeitas mútuas, e quem sabe que mais? (THOMAS, 1931, p. vii).

Para enfrentar a desconfiança dos governos, trabalhadores, empresários e o descaso da opinião pública, Albert Thomas apelou aos diplomatas que residiam em Genebra e Paris e ainda, fez constantes viagens pelo mundo todo, difundindo, apresentando, discutindo e tentando convencer aos seus interlocutores sobre a importância da existência da OIT e da necessidade de implantar a legislação acordada nas Conferências Internacionais do Trabalho. Embora as viagens fossem freqüentes e pelo mundo todo, os resultados não pareciam muito alentadores, ao ponto que uma das criticas mais freqüentes a Albert Thomas foi nos seus longos períodos de ausência de Genebra e na falta de resultados de estas viagens. ${ }^{17}$

Foram tantas as viagens de Albert Thomas dentro da Europa eram que aquelas que eram realizadas no eixo Roma, Londres, Berlim não eram informadas pelos seus colaboradores, assim parecia que ele permanecia no seu escritório, o mesmo para aquelas que ele realizava a Paris. Para ter uma idéia do esforço e da importância dada a estas viagens Albert Thomas passou uma média de seis meses fora de Genebra visitando 29 países nos seus doze anos como Secretario geral da OIT. Além de Thomas, vários dos seus colaboradores empreenderam viagens de apresentação da OIT e de negociações para a aprovação das Convenções. E mesmo com todo o esforço realizado, as criticas foram muitas (MASSART, 1993, p. 126).

Estas viagens permitiam reforçar o elo com a Sociedade de Nações, embora de tanto em tanto pudessem criar algum atrito com a mesma, pelas concepções divergentes sobre a diplomacia e a ação da OIT. Por outro lado, também pretendia tanto dar a conhecer a ação da OIT e estabelecer a sua importância em participar de questões econômicas por sobre a própria SdN (MASSART, 1993, p. 90-91, 96,102, 104). 18

Três destas viagens tiveram características diferenciadas porque implicaram uma preparação e um tempo de ausência superior à média: no final de 1922 e inícios de 1923

17.- Sobre a falta de resultados, é só analisar os quadros apresentados anteriormente.

18. Sylvie Massart (1933, p. 90-104) faz uma interessante analise destes elementos, sobre a relação com a Sociedade das Nações e alguns atritos com a mesma. Sobre a intenção de estabelecer a primazia na questão econômica. 
foi aos Estados Unidos; em 1925 visitou o Cone Sul da América e a última grande viagem foi em 1929 em direção ao J apão, passando por Moscou (GUERIN, 1996, p. 2829). A que nos interessa, foi a única que ele fez à América Latina. A escolha se deveu a que nesta região estavam os países que mantinha um contato freqüente com o Escritório e com os seus membros. Os países designados para esta visita foram: Brasil, Uruguai, Argentina e Chile, na ordem em que foram visitados.

Na Sexta Sessão do encontro em 26 de junho de 1924, o representante governamental chileno, Armando Quezada Acharán, convidou a Albert Thomas a fazer uma viagem ao Chile no meio de uma longa apresentação explicando qual era a situação trabalhista no Chile (LEAGUE OF NATIONS, 1924, p. 41). Mas, não foi o único pedido de Quezada, ele também solicitou a criação de um serviço de correspondentes na América Latina, questão que seria recolocada durante a viagem. Tanto o convite para visitar o Chile quanto a criação do serviço de correspondentes eram pensados por Quezada como um forma de ampliar a publicidade da obra da OIT na América Latina e como essa publicidade seria fundamental na implementação de uma política trabalhista. Sendo um representante governamental ele entendia que a obra do Estado era menos eficaz que a publicidade, deslindando responsabilidades pela impossibilidade de ratificar as Convenções. O Chile mostrou o seu compromisso com a OIT criando um escritório dentro do país para divulgar e acompanhar a obra da instituição de Genebra. ${ }^{19}$

O pedido para realizar a visita foi secundado por Mario Negri, representante operário da Argentina por La Fraternidad a associação de trabalhadores nas Estradas de Ferro; e por Affonso Bandeira de Mello, representante governamental brasileiro e Secretario Geral do Conselho Nacional do Trabalho no Brasil. Segundo Bandeira de Mello, a visita lhe permitiria a Albert Thomas um estudo mais aprofundado da situação econômica e social da América Latina, dando continuidade à melhora nas leis sociais. Já Negri, entendia que a viagem aprofundaria a colaboração destes países com a obra da OIT e favoreceria a aproximação com os trabalhadores.

A visita foi relativamente curta, pensando na travessia realizada, e a diferencia de outros viajantes do período a escolha foi a de fazer o maior percurso possível por via férrea, aproveitando cada parada para conhecer essas cidades e as suas questões específicas. Ficou no território americano entre 15 de julho e 22 de agosto Albert Thomas percorreu os quatro países antes mencionados, onde manteve encontros com a imprensa, com trabalhadores, representantes do governo e empresários. Ele participou

\footnotetext{
19. Quem impulsionava esta política era o Diretor do Escritório do Trabalho do Chile, Moisés Poblete Troncoso, quem posteriormente foi incorporado à estrutura da instituição e realizou um dos estudos pioneiros sobre o trabalho indígena na América Latina.
} 
de palestras, banquetes, comícios e reuniões. Manteve conversas com os presidentes e com trabalhadores sem filiação. A expectativa era a de construir um panorama da região, em primeira mão, analisar as perspectivas e balizar as ações a serem tomadas. Todos os passos foram previamente medidos, mas sobrou lugar para o imprevisto. A viagem teve múltiplas narrativas. Desde o informe definitivo elevado à Conferência Internacional do Trabalho até as notas rabiscadas pelo próprio Thomas.

A viagem foi preparada minuciosamente, todos os passos foram medidos e calculados. A equipe de Albert Thomas e ele próprio prepararam com cuidado cada passo a ser dado, sem descuidar a data de retorno para atender às atividades periódicas da OIT, como a Conferência internacional dos Ministros do Trabalho sobre as 8 horas de trabalho que se reuniria em sete de setembro de 1925, pouco depois da chegada. ${ }^{20}$ Para compreender o nível de detalhe com que foi diagramada esta viagem nas pastas depositadas na OIT encontramos artigos jornalísticos sobre o "mal do mar"; as dimensões e comodidades dos barcos que poderiam ser utilizados; a lista de livros sobre os países a serem visitados para ler durante a viagem de ida; a relação de documentos levados para trabalhar durante a viagem; entre tantos outros preparativos. ${ }^{21}$

Nestes mais de 30 dias a viagem foi estabelecida para ficar igual número de dias no Brasil, Argentina e Chile, e uma estada menor no Uruguai. Albert Thomas integrou a sua comitiva com o seu chefe de gabinete, Marius Viple; do chefe da seção de relacionamentos, Di Palma Castiglione; o seu secretário pessoal, Lebrun; e de Fabra e Rivas, Diretor do Bureau em Madri e das Informaciones Sociales, publicação em espanhol da própria OIT. Além deles iriam um funcionário brasileiro, Soares de Souza, e outro chileno, García Palacios, que acompanhariam a Albert Thomas aos seus respectivos países. A partida foi no dia 30 de junho, chegando ao Rio de J aneiro em 14 de julho. Chegou ao Uruguai em 26 de julho e na Argentina o dia 30 de J ulho. Desde o dia 7 a 14 de Agosto ficaram no Chile, passando novamente pela Argentina entre 16 a 18 de agosto e finalmente chegou ao Rio de Janeiro o dia 22 de agosto, data da partida definitiva para a Europa, onde arribaria no dia 7 de setembro de 1925.

Para além dos percursos da viagem é bom determinar quais eram os objetivos que Albert Thomas se colocava nesta viagem. Havia objetivos de diversa ordem e de distinta natureza, que não necessariamente tratavam questões de tipo trabalhistas. Todos estes objetivos estavam dentro da concepção que Thomas tinha da OIT e da importância que

20. Carta de Marius Viple a M. Soares de Souza. CAT 1/25/2/5 Arquivo da OIT, Genebra.

21. Cabinet Albert Thomas (CAT) Dossier: 1-25-2 “Voyages Juillet-Aout 1925 - Organisation Voyage Amerique Latine"; CAT 1/25/2/ 1 Programme Voyage Amerique Latine; CAT 1/25/2/2; e CAT 1/25/2/ 3: Voyage Amerique Latine. Organisation Materiélle; todos no Arquivo da OIT, Genebra. 
ele atribuía a estas viagens. Para reforçar as suas relações com a $\mathrm{SdN}$, levou a preocupação com os exilados russos produto da guerra civil entre russos brancos e comunistas. Outro objetivo era revisar a marcha das convenções da OIT e as da SdN. Outra amostra da interação entre as duas instituições ou, ao menos, a sua situação de auxiliar da OIT em relação à SdN. Do Brasil esperava-se que ratificasse alguma das Convenções, ou quanto menos a Recomendação 6 de 1919 que tratava do fósforo branco. Ainda quando a legislação trabalhista brasileira contemplasse algumas das convenções, as mesmas não eram ratificadas. Do Uruguai esperava-se algo similar. Argentina era um caso diferente porque se bem todas as convenções tinham sido enviadas ao Parlamento, o problema residia nos conflitos políticos parlamentares que impediam a sua ratificação. O caso do Chile era um tanto diferente devido a que se tinha comprometido a aprovar os convênios como parte da viagem de Albert Thomas e, por tanto, o governo deste país não era cobrado como os outros países. ${ }^{22}$

Coincidentemente com as preocupações já estabelecidas pela OIT, havia outros objetivos que excediam a questão dos Estados. Os outros dois setores que conformavam a organização tripartite também estavam no interesse da comitiva. Os patrões deviam ser cortejados e convencidos da importância da aceitação das propostas da OIT e que fossem agentes de difusão dos benefícios da aceitação dos seus postulados. Este objetivo não era menor nem apresentava complicações. Os patrões nem sempre estavam de acordo com a ampliação dos direitos trabalhistas e muitas vezes apelavam às formas de controle do trabalho tradicionais ou viam no fascismo uma saída muito mais profícua que a OIT.

Entre os trabalhadores as dificuldades pareciam ser similares. O anarquismo e o comunismo apareciam como opções mais influentes, ou pelo menos isto era o que entendia Albert Thomas. Porém, a falta de comprometimento dos trabalhadores com a OIT estava na apropriação que distintos setores faziam da mesma. Se na Argentina a OIT era apoiada pelo socialismo e os sindicatos ligados a este partido, no Chile o interesse do Estado nesta instituição levava à desconfiança por parte dos trabalhadores que não estavam interessados num vinculo forte com o Estado e que tinham no PC o seu principal fonte de agregação. Por tanto, apoiar ou não à OIT dependia muito mais das situações locais do que das leituras iniciais de Thomas.

Thomas era consciente de que as viagens em si mesmas não tinham um grande impacto no país visitado e que depois de um primeiro momento de interesse o mesmo se desvanecia. Ele compreendia que os logros que se alcançavam nesse primeiro

\footnotetext{
22. O informe sobre a viagem apresentado na na Revista Internacional do Trabalho em finais de 1925 tanto apresenta as expectativas prévias sobre a viagem como os resultados da mesma. (INTERNATIONAL LABOUR ORGANIZATION, 1925).
} 
momento eram decisivos e sempre restava monitorar de perto a situação de cada país e ampliar a rede de informantes. Nos resultados, o tramo chileno da visita foi o mais bem sucedido, ao ponto que durante a presença da comitiva nesse país foram aprovados oito convenções. O que representou um dos principais logros da viagem e da OIT, considerando de que nenhum dos outros países visitados tinha ratificado convenção alguma até esse momento (INTERNATIONAL LABOUR ORGANIZATION, 2010). ${ }^{23}$

O outro avanço considerado como significativo foi estabelecer vínculos com as dependências dos Estados da região que acompanhavam a questão trabalhista, em quase todos os casos denominados de Direções Nacionais do Trabalho, excetuando no Brasil que se denominava Conselho do Trabalho. Estes vínculos tinham como prioridade a obtenção de informação sobre as condições de vida, de trabalho, sobre os níveis de sindicalização, quantidades de trabalhadores por indústrias, entre outras tantas informações solicitadas pela OIT (INTERNATIONAL LABOUR ORGANIZATION, 1925, p. 771). Na manutenção do fluxo das informações, também se pretendia que aquilo que acontecia em Genebra tivesse repercussão no Cone Sul. Para isto se fez uma intensa propaganda e foi procurada a forma de vender a revista da OIT em espanhol Informaciones Sociales. O encarregado dessa tarefa foi Antoni Fabra i Ribas, o editor das Informaciones, estreito colaborador de Albert Thomas e membro do Partido Socialista Operário da Espanha (PSOE). Fabra conseguiu vendedores, fez convênios com instituições de analise das questões sociais, como o Museo Social na Argentina, e ainda ele próprio vendeu assinaturas da revista. Tudo isto pela importância dada à publicidade e a circulação das informações por parte da OIT. ${ }^{24}$

Também foi ressaltado como resultado da viagem o fato de que no ano de 1925 os países da região tivessem enviado delegações completas, como é informado no relatório da viagem apresentado na Revista Internacional do Trabalho (INTERNATIONAL LABOUR ORGANIZATION, 1925, p. 765). Até esse momento, as delegações eram conformadas basicamente por representantes do Estado e, ocasionalmente, por algum representante patronal. A exceção era a Argentina que tinha enviado representações completas. ${ }^{25} \mathrm{Na}$ realidade esta era um exagero. O envio das representações completas

23.- C1 de 1919, Lei de oito horas; C3 de 1919, Proteção da maternidade; C5 de 1919, Idade mínima para trabalhar; C6 de 1919, Trabalho noturno de menores; C11 de 1921, Direito de associação dos trabalhadores na agricultura; C12 de 1921, Indenização por acidente de trabalho na agricultura; C13 de 1921, Contra o emprego do alvaiade na pintura; C14 de 1921, Sobre o repouso semanal na indústria. Até esse momento a C1 tinha sido ratificada por 8 países; C3 por 4 países; o C5 por 9 países; o C6 por 16 países; o C11 por 14 países; C12 por 8 países; C13 por 7 países; e C14 por 11 países.

24. Notes pour le directeur.Les "Informaciones Sociales" et les publications du B.I.T. 25/ 10/1925 IN: CAT $1 / 25 / 3 b / 3$.

25. A Argentina enviou representações completas em 1919, 1920, 1924 e 1925, em 1921 e 1922 não enviou representante, em 1923 unicamente enviou ao representante do Estado. Brasil, foi o caso 
restringiu-se a Argentina e Chile que enviaram as suas delegações completas, o Brasil não enviou o representante dos trabalhadores e o Uruguai só enviou um representante do Estado, nem mesmo dois como era regulamentar. Por outro lado, o envio de delegações completas não implicava, nem implicam ainda hoje, a independência dos delegados. Na Primeira Conferência Internacional, em 1919, se produziu um interessante debate sobre a natureza do delegado operário argentino. Ele era um legitimo representante dos trabalhadores ou na realidade a escolha feita pelo governo era para favorecer as suas posições? (LEAGUE OF NATIONS, 1920, p. 109-113). ${ }^{26}$

Outra forma de recavar informação se dava mediante a designação de correspondentes. O escritório de correspondência era uma instituição que a OIT estava colocando em prática como uma forma de manter uma comunicação permanente sobre o que acontecia nos países em que atuava. Os países que recebiam os correspondentes eram aqueles que mais chamavam a atenção da OIT, os países industrializados. Ou seja, aqueles que tinham um grande contingente operário e com uma forte tradição de militância sindical. A existência dos correspondentes, em palavras de Albert Thomas, permitia obter informação de primeira mão, rompendo o isolamento livresco em que estava o Escritório em Genebra. Porém, a visão do correspondente era um tanto sesgada, preferia-se o correspondente com o qual se pudesse manter relação imediata. Por ex., Albert Thomas tinha receios sobre o esforço do correspondente que residia no J apão, para ele a distancia dificultava o acesso direto à informação e, ao mesmo tempo, não podia ter contato direto com o seu informante. Havia dois tipos de correspondentes: os correspondentes que eram funcionários diretos da OIT, que eram os que estavam sediados em Washington, Londres, Paris, Roma, Berlim e Tóquio. E os correspondentes sem vínculo permanente e que eram os que estavam sediados em Varsóvia, Madri, Viena, Budapeste, Bruxelas e Praga. (LEAGUE OF NATIONS (1924, 1925). E mesmo com o pouco interesse de Thomas em ter correspondentes longe do seu alcance, fossem funcionários diretos da OIT ou não, os sul-americanos pretendiam que a OIT aceitasse a presença destes novos funcionários. Os países do Cone Sul pretendiam ser melhor considerados ao interior da OIT passando a ter o mesmo rango que os países europeus.

mais complexo: em 1919 envio o representante do Estado e o operário, em 1920 não teve representação; em 1921 e 1922 unicamente assistiu o representante do Estado; em 1923 e 1925 a representação foi completa; e em 1924 unicamente assistiram o representante do Estado e o patronal. Chile: enviou sempre representantes do Estado, com exceção do ano de 1925 quando a delegação foi completa. O Uruguai enviou representantes governamentais todos os anos. Os dados sobre a participação nas Atas das Conferências Internacionais desses anos.

26. A credencial do delegado foi finalmente aceita, mas colocava uma dúvida sobre o processo de seleção dos representantes. Esta questão relacionada aos re operários continua viva ainda hoje. 
Entre as atividades de Albert Thomas, também foi acompanhada a situação da SdN na região. Excetuando o caso argentino, que tinha uma política isolacionista e contraria à Sociedade pela sua política em relação aos países neutrais (ESCUDÉ, 2000), ${ }^{27}$ os outros países aderiam, mas com pouco interesse. Por tanto, o reforço dos vínculos com os Ministérios de Relações Exteriores destes países também foi colocado como tarefa prioritária. O melhor resultado foi obtido no Brasil que estabeleceu uma embaixada junto à Sociedade, e que também contaria com um representante destinado às questões próprias da OIT, e no Brasil, estabeleceu uma dependência no Ministério das Relações Exteriores, para acompanhar às ações da Sociedade. Já Argentina optou pela criação de um cargo para monitorar as questões relacionadas à OIT, o que de por si era alentador se comparado com o desinteresse pela SdN. A pretensão de Thomas era que estes países criaram o cargo de Adido Social ante a OIT, assim como existiam os adidos sociais nas embaixadas da Alemanha em Roma e da Suécia em Berlim (OIT, 1925, p. 772). ${ }^{28}$

Até o momento temos feito uma serie de analises sobre as questões de interesse para a OIT e daquelas que interessavam aos países da América do Sul que foram visitados pelo Secretario Geral da OIT. Como falamos anteriormente, os resultados não foram muito alentadores, já que não se verificou um aumento do nível das ratificações nem a OIT se mostrou interessada em continuar com o vinculo. ${ }^{29}$ Também a OIT demorou vários anos para pôr em funcionamento o sistema de correspondentes, assim como a região não colocou em prática os mecanismos de aproximação entre as partes que foram negociadas ou anunciadas. Do ponto de vista prático foi um fracasso, porém, a viagem não deve ser medida unicamente de essa forma. Muitos contatos foram estabelecidos, alianças foram reforçadas e a troca de informações se incrementou significativamente. Algumas temáticas apareceram em cena, como a questão do trabalho indígena proposta pelo Chile, e a imagem da América mudou na percepção da administração da OIT.

27. Para maiores dados sobre a relação da Argentina com a Sociedade de Nações. A política tinha sido estabelecida pelo presidente Irigoyen, seu sucessor Marcelo Alvear, embora do mesmo partido, procurava uma distensão com a Sociedade, como expressa numa carta que envia a Thomas: Carta de Marcelo de Alvear a Albert Thomas, 30/ 07/ 1924 IN: CAT 1/ 25/3b/ 1.

28. Sobre a dependência destinada à Sociedade das Nações no Brasil. A informação sobre a existência da Embaixada brasileira destinada à Sociedade de Nações em Genebra está num informe manuscrito entregue a Albert Thomas por um colaborador. “Le role dês questions sociales dan's le Estat moderne" IN: CAT 1/25/3b/3.

29. A primeira ratificação da Argentina aconteceu em 1933; a do Brasil foi em 1934; e a do Uruguai também foi em 1933. O caso do Chile já foi comentado anteriormente. 


\section{Uma Reflexão Final Sobre a Viagem e o Viajante}

Para finalizar, vamos voltar sobre uma questão antes mencionada: o eurocentrismo de Albert Thomas. A coleção de documentos sobre esta viagem tem um pequeno diário de viagem em que Thomas narra as suas impressões, as suas expectativas e os seus prejuízos, fossem estes positivos ou negativos.

Certamente o eurocentrismo de Thomas é importante na medida em que repercute na conceição do relacionamento que devia ser construído com a América Latina. Falar em América Latina é muito amplo, porém, esta é a terminologia utilizada por Albert Thomas. Este termo, heterogêneo e amplo demais, tem como objetivo unificar o conjunto e, dessa forma, poder compará-lo com o seu ponto de referencia a Europa. Desta forma Albert Thomas utilizou suas referências culturais para avaliar a "Democracia”, o que lhe permitiria estabelecer uma comparação com a Europa. Se bem Thomas apresenta uma grande empatia pessoal com a América Latina, esta empatia se manifestava em elementos que refletiam a Europa ou que ao menos se assemelhavam a ela.

As palavras de Thomas fazem constantemente referência à Europa como parâmetro nos elogios ou nas criticas. Dessa forma se elogiou à Argentina em detrimento do Chile pelo fato de ter menos descendentes de europeus ou pela defesa dos valores de justiça e democracia. ${ }^{30}$ Na realidade a aposta na América Latina, está diretamente relacionada com as disputas em torno da continuidade da OIT e da Sociedade de Nações. A viagem para a América do Sul tinha por objetivo desativar o Panamericanismo que os Estados Unidos tentavam pôr em funcionamento. Há um grande esforço para tentar trazer aos estados da região para a SdN, num momento em que os Estados Unidos reafirmavam a sua opção pelo isolamento e que o comunismo era visto como uma ameaça para a democracia. Paradoxalmente, o fascismo não foi mencionado como um opositor ao sistema da SdN.

Os países da América do Sul foram apresentados como um espelho para o J apão, país ao que Thomas via numa encruzilhada. O J apão optava pelo pan-asiatismo, que o levaria a uma relação de proximidade com o bolchevismo; ou se universalizava, e por tanto aceitava os valores europeus. E isto era o que Albert Thomas, e por intermédio dele a SdN, pretendia que a América do Sul não transitasse por esse caminha. No caso da América do Sul era a sua aproximação aos Estados Unidos e o afastamento da Europa. Para ele, o caminho da região devia ser a universalização e a universalização correspondia a associar-se com a SdN, ou seja, a opção pela Europa. O pequeno diário

30. CAT 1/25/3b/3 e CAT 1/25/7/1 (Voyage Amerique du Sud - Juin 1925): Note pour le travail personnel sur mon voyage en Amerique du Sud. 
de viagem, que ele intitulou como Note pour le travail personnel sur mon voyage en Amerique du Sud, traz uma reflexão sobre como a democracia e o pensamento destes países são profundamente europeus, fazendo elogios aos pensadores (como Echeverria, Alberdi e Sarmiento) como os heróis independentistas (como San Martín, Bolívar e Nariño) são heróis da humanidade. A aproximação da América do Sul com a Europa, justamente devia dar-se neste universalismo dos posicionamentos da região nos seus próprios conflitos, remarcando o lema da Doutrina Drago: “América para a Humanidade", oposto à Doutrina Monroe; e a outra consigna que era "A vitória não dá direitos" com que concluíram as tratativas da Guerra do Paraguai. ${ }^{31}$

Estes preceitos que Thomas entendia que eram os reitores da política da América do Sul eram os princípios que ele definia como civilizados e, por tanto, europeus. A America que se civilizava e que aceitava os padrões de conduta da raça branca, esta era a América que podia entrar em acordo com a Europa da SdN e que devia afastar-se do caminho do pan-americanismo hegemonizado pelos Estados Unidos. A América do Sul, alheia sempre aos conflitos bélicos europeus, era uma espécie de reserva estratégia na defesa dos valores democráticos e dos valores da justiça social, como valores europeus e, por tanto, universais. Esta América do Sul, idealizada certamente pela situação, era a América Latina que pretendiam incorporar ao sistema da SdN. Todo o esforço realizado na viagem pode não ter sido frutífero, porém não deve ser desdenhada a tentativa de criar um elo com a Europa, por meio da viagem e da construção de um sistema legal para o mundo do trabalho que unificasse ao Antigo e ao Novo mundo.

\section{Referências}

ELEY, Geoff. Forjando a democracia: a história da esquerda na Europa, 1850-2000. São Paulo: Fundação Perseu Abramo, 2005.

ENDRES, Anthony; FLEMING, Grant. International organizations and the analysis of Economic Policy, 1919-1950. New York: Cambridge University Press, 2002.

ESCUDÉ, Carlos; CISNEROS, Andrés. Historia de las relaciones exteriores argentinas. Buenos Aires: CARI, 2000. pte 2, t. 8.

GOVERNING BODY OF THE INTERNATIONAL LABOUR OFFICE. Minute of the first session. Washington: ILO, 1920.

\footnotetext{
31. A Doutrina Drago foi enunciada pelo Chanceler argentino Luis Maria Drago que em 1902 se opõe ao Corolário Roosevelt da Doutrina Monroe; "A vitória não dá direitos" é o principio reitor da Doutrina Varela, enunciada por Mariano Varela, chanceler de Sarmiento, como forma de concluir a Guerra do Paraguai.
} 
GUERIN, Denis. Albert Thomas au BIT, 1920-1932: de l'internacionalisme à l'Europe. Genebra: Institut Européen de Gèneve, 1996.

INTERNATIONAL LABOUR ORGANIZATION. ILOLEX: database of international labour standards. Disponivel em: <http:// www.ilo.org/ilolex/ english/ newcountryframeE.htm>. Acesso em: $20 \mathrm{~J}$ un. 2010.

INTERNATIONAL LABOUR ORGANIZATION. The visit to south america of the director of the International Labour Office. International Labour Review, Geneva, v. 12, n. 6, p. 757-775, dez. 1925.

LEAGUE OF NATIONS. First and second parts. In: INTERNATIONAL LABOUR CONFERENCE, 16., 1924, Geneva. Anais.... Geneva: International Labour Office, 1924. p. 41.

. International labor conference: first anual meeting. Washington: Goverment Printing Office, 1920.

. Report of the Director. In: INTERNATIONAL LABOUR CONFERENCE, 16., 1924, Geneva. Anais.... Geneva: International Labour Office, 1924. p. 57.

Report of the Director. In: INTERNATIONAL LABOUR CONFERENCE, 17., 1925, Geneva. Anais.... Geneva: International Labour Office, 1925. p. 44.

MARX, Karl. A dominação britânica na Índia. 1853. Disponível em: <http:/ / www.marxists.org/ portugues/ marx/ 1853/06/ 10.htm>. Acesso em: 24 J ul. 2010.

MARX, Karl. Simon Bolivar por Karl Marx. Rio deJ aneiro: Martins Fontes, 2008.

MASSART, Sylvie. Les voyages d'Albert Thomas, directeur du Bureau International du Travail, 1919-1932. Paris, 1993.

ORGANIZAÇÃO INTERNACIONAL DO TRABALHO. Cláusulas de los tratados de paz relativos al trabajo. Genebra: OIT, 1919.

ORGANIZACION INTERNACIONAL DEL TRABAJ O. Albert Thomas. 2006.

Disponível em: <http:/ / www.ilo.org/ public/ spanish/ bureau/ dgo/ staff/ formers/ thomas.htm>. Acesso em: 15J un. 2010.

ORGANIZACIÓN INTERNACIONAL DEL TRABAJ O. Origenes e historia. Disponible em: <http:// www.ilo.org/global/ About the_ILO/Origins_and_history/lang-es/index.htm>. Acesso em: 14 J un. 2010.

RODGERS, Gerry; SWEPSTON, Lee; LEE, Eddy; VAN DAELE, J asmien. La Organización Internacional del Trabajo y la lucha por la justicia social, 1919-2009. Genebra: OIT, 2009.

SAID, Edward. Cultura e imperialismo. São Paulo: Companhia das Letras, 1999.

SOUZA, Tancredo Soares de. Albert Thomas. Falecido como diretor da repartição do Trabalho da Sociedade das Nações. Rio de J aneiro: Typ. São Benedito, 1933. 
THOMAS, Albert. La Organización Internacional del Trabajo, origen, evolución y porvenir. Revista Internacional del Trabajo, Ginebra, v. 115, n. 3-4, p. 283-299, 1996.

THOMAS, Albert. Le second Empire. In: J AURÈS, J ean. Histoire socialiste: (18521870). Paris, 1901. (Colection sous la direction de J ean J aurès.)

THOMAS, Albert. Preface. In: . Dix ans d'Organisation Internationale du Travail. Genebra: Bureau International du Travail, 1931. p. i-xv.

TOSSTORFF, Reiner. The International Trade Union Movement and the founding of the International Labour Organization. Inaternational Review of Social History, Assen, v. 50, p. 399-433, 2005.

UNSAÍN, Alejandro. Organización Internacional del Trabajo. Revista J urídica y de Ciencias Sociales, Buenos Aires, abr./jun. 1925.

VAN DAELE, J asmien. Engineering social peace: networks, ideas, and the founding of the International Labour Organization. Inaternational Review of Social History, Assen, v. 50, p. 435-466, 2005.

Colaboração recebida em 29/ 06/ 2010 e aprovada em 09/08/2010. 